\title{
The role of bondline thickness on mechanical properties of bio-based polyurethane
}

Paulo Henrique Lixandrão Fernando ${ }^{1}$, Cleber Lucius da Costa ${ }^{1}$, Kelly Cristina de Lira Lixandrão ${ }^{1}$, Demetrio Jackson dos Santos ${ }^{1}$

\author{
${ }^{1}$ Engineering, Modeling and Applied Social Sciences Center, ABC Federal University (UFABC), Santo André, São Paulo, \\ Brazil. \\ e-mail: demetrio.santos@ufabc.edu.br
}

\begin{abstract}
Bio-based adhesives have been largely applied on several applications in many industrial areas, including automotive and laminated food packaging. Polyurethanes (PU) occupy a leading position among the most used bio-based polymers due to their large range of properties and application versatility. Recent works reported that PU obtained from castor oil and Kraft lignin as polyol developed high mechanical properties and blend miscibility. In spite of its well-known mechanical behavior, additional investigations might support the application of this bio-based PU as adhesive. In this context, our work investigated the effect of adhesive (bondline) thickness variation (size effect) on shear modulus of a bio-based polyurethane under finite deformation and related shear stress distribution. Polyurethane was obtained using a blend of Kraft lignin and castor oil as polyol (20 wt\% of Kraft lignin) and applied as adhesive for metal bonding, in which adhesive thickness changed from tens of micrometers up to 220 micrometers. Steel plates were used as substrates and adhesive shear modulus was evaluated using substrates with large thickness $(4.76 \mathrm{~mm})$, which minimized the effect of substrate deformation on shear modulus measurement. Single lap joints were uniaxial loaded in order to generate the shear stress on adhesive bondline. Additionally, shear modulus changes were simulated by finite element analysis (FEA), analytical models and compared to experimental data. Results revealed the size effect and pointed to high shear modulus of the PU bondline, justifying its use as an adhesive for structural applications.
\end{abstract}

Keywords: bio-based polyurethane, Kraft lignin, finite element analysis, adhesive.

\section{INTRODUCTION}

The dependence of adhesive shear modulus $(G)$ on bondline thickness, known as size effect, was extensively investigated in the last decade [1,4]. Authors demonstrated that changes of adhesive thickness might affect shear modulus, as a consequence of metallic substrate influence on polymeric structure and properties. In few words, thinner adhesive films are strongly affected by the interface with the metallic surface, in comparison to thicker bondlines for which bulk properties are predominant. Nevertheless, shear stress distribution is also a significant property of adhesively bonded joints subject to shear and combined loadings [5,6].

To the best of our knowledge, the size effect of only isotropic epoxy and polyurethane adhesives were investigated concerning size effect. Shear or effective modulus of these adhesives was usually stabilized for bondline thickness around $200 \mu \mathrm{m}$ and thicker. In this work we investigated the size effect up $220 \mu \mathrm{m}$ thickness and shear stress distribution of a bio-based polyurethane adhesive, in which castor oil and Kraft lignin were used as polyol. Kraft lignin is a natural polymer with a complex phenolic structure. It is available at industrial scale as a byproduct of pulp and paper manufacturing [7,9]. An increasing interest in the development of lignin based products has emerged over the last years, triggering its use as a raw material for several polymer products $[10,13]$. Notwithstanding, the powder state of unmodified lignin restricts its application, due to its inherent poor dispersion in many polymer matrices, including polyurethane $[14,15]$.

The purpose of this work was to investigate if lignin can eliminate or hidden the size effect of lignincontaining polyurethanes. Mechanical tests for size effect investigation were carried out under shear loading, which requires an additional elucidation of shear stress distribution in the adhesive layer [16]. Furthermore, shear stress concentration at edges of single lap joints is a well-known behavior and strongly depends on the following parameters: metallic substrate dimensions and mechanical properties, adhesive properties, bondline 
thickness and overlap length. Once size effect was investigated and shear stress distribution was elucidated, finite element method was applied to simulate the mechanical behavior of the adhesive layer.

\section{MATERIALS AND METHODS}

\subsection{Materials}

Polyol was obtained by mixing castor oil and Kraft lignin. Kraft lignin was kindly supplied by Suzano Papel e Celulose (Suzano, Brazil), as a byproduct of pulp and paper manufacturing, with pH 8.5, brown color, 255

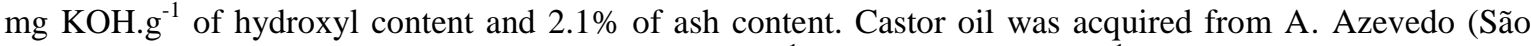
Paulo, Brazil) with hydroxyl index of $169 \mathrm{mg} \mathrm{KOH} . \mathrm{g}^{-1}$ and $0.95 \mathrm{mg} \mathrm{KOH} . \mathrm{g}^{-1}$ of acid index. Diphenylmethane diisocyanate (MDI) was purchased from Kalium Chemical (São Paulo, Brazil) for polyurethane synthesis, with NCO content of $31 \%$.

\subsection{Single lap joints}

Steel (SAE 1010) laps with dimensions of 4.76 × 25.4 x $100 \mathrm{~mm}$ and Poisson ratio of 0.30 were used as substrates $[17,18]$. Steel surfaces were mechanically treated in order to control and minimize roughness. Single lap specimens are presented in Figure 1. They were bonded using a polyurethane adhesive to form the adhesively bonded lap shear joint. A blend of Kraft lignin (20 wt \%) and castor oil was used as polyol. PU was obtained by mixing the lignin-containing polyol with MDI (molar ratio NCO:OH of 1.2:1). The adhesive was applied on both laps. Parts were put together and kept under constant pressure (grips), generating a bonded length (overlap) of $40 \mathrm{~mm}$. Next, the lap joints were cured for seven days at room temperature. PTFE films were used to control the bondline thickness $(130 \mu \mathrm{m}$ up to $220 \mu \mathrm{m})$, whose values are shown in Table 1 . Optical microscopy analysis was carried out to measure the adhesive layer thicknesses, after curing.

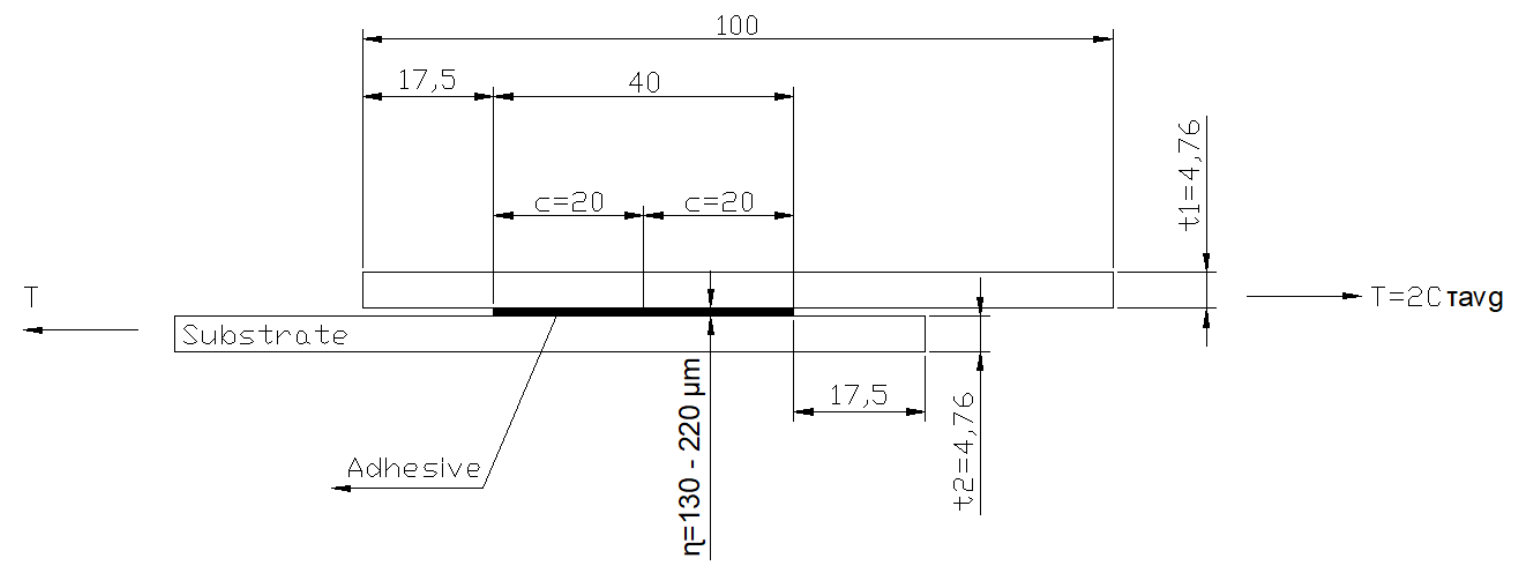

Figure 1: Geometry and materials parameters of the single-lap joint.

Table 1: Thickness of adhesive layer (bondline)

\begin{tabular}{c|c|c|c|c}
\hline $\mathbf{A 1}-\mathbf{B 1}$ & $\mathbf{A 2}-\mathbf{B 2}$ & $\mathbf{A 3 - B 3}$ & $\mathbf{A 4 - B 4}$ & $\mathbf{A 5 - B 5}$ \\
\hline $130 \mu \mathrm{m}$ & $150 \mu \mathrm{m}$ & $160 \mu \mathrm{m}$ & $180 \mu \mathrm{m}$ & $220 \mu \mathrm{m}$ \\
\hline
\end{tabular}

\subsection{Confocal Laser Scanning Microscopy}

Confocal laser scanning microscopy (CLSM) was employed (Olympus LEXT OLS4100) to examine surface topography and determine its roughness. Ten lines with length of $1280 \mu \mathrm{m}$ were measured on three specimens. Afterwards, the average surface roughness ( $\mathrm{Ra}$ ) was calculated according to ISO 4287/2002 [19].

\subsection{Single lap shear test}

Single lap shear specimens (five specimens) were tested according to ASTM D 1002-99 [20] using an Instron Universal testing machine, model 3369, equipped with a load cell of $50 \mathrm{kN}$ and crosshead speed of 1 
$\mathrm{mm} \cdot \mathrm{min}^{-1}$. High thickness of the steel substrates ensured infinitely higher shear modulus when compared to adhesive shear modulus. This condition allows neglecting substrate deformation under shear and to consider exclusive adhesive deformation.

\subsection{Simulation of the adhesive layer behavior}

Firstly, adhesive behavior (under shear loading) was simulated with a ANSYS finite element software [21]. The adhesive layer was considered isotropic and modeled using an 8-node mesh, with three degrees of freedom (DOF) and 30184 elements. Secondly, traditional models (Volkersen, Gosland and Reissner) were applied for comparison with FEM and experimental results [22, 23].

\section{RESULTS AND DISCUSSION}

\subsection{Confocal Laser Scanning Microscopy}

Figure 2 shows a roughness profile of the treated steel surface obtained by CLSM. An average roughness of $2.987 \mu \mathrm{m}(\mathrm{Ra})$ was determined. This value cannot be taken as significant, since the thinnest adhesive layer presented $130 \mu \mathrm{m}$ of thickness. Thus, the substrate roughness is too low in comparison to the adhesive layer thickness. Based on the low roughness and homogeneous topography, we can assume that irregularities of metallic substrate do not affect the results of the mechanical tests.

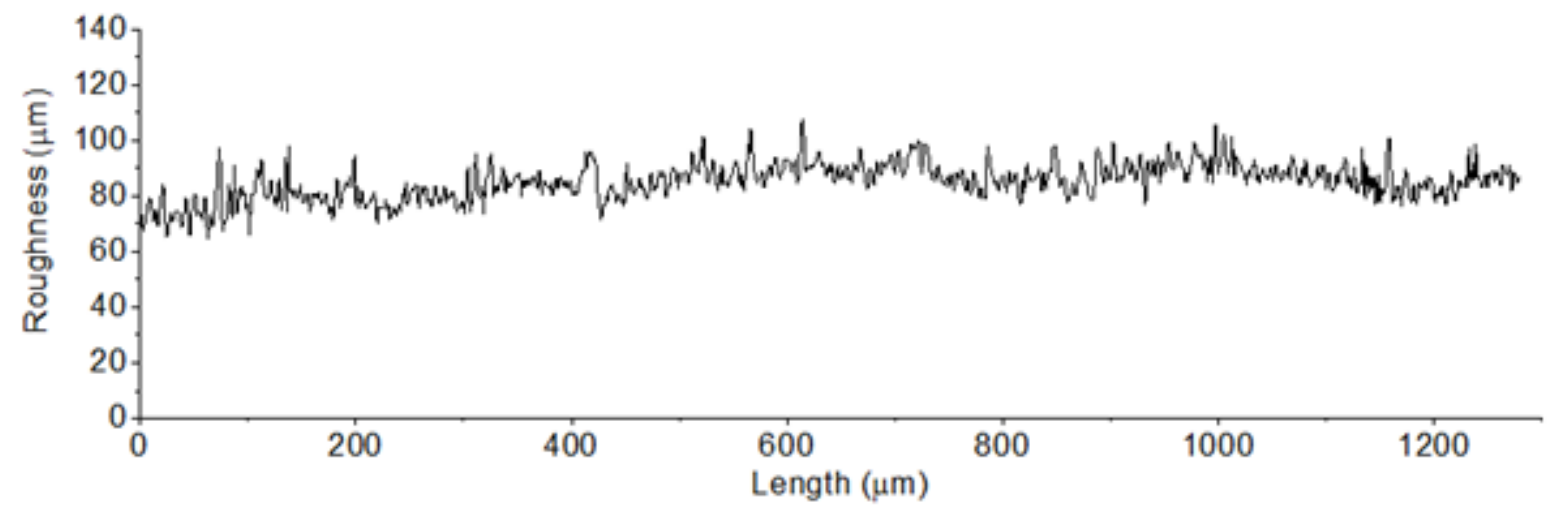

Figure 2: Representative roughness profile of the steel surface (adherent).

\subsection{Experimental results}

As previously mentioned, size effect refers to effective modulus changes (shear modulus) as a consequence of varying adhesive layer thickness [1]. Assuming shear modulus as a material property, it could be contradictory to consider it as thickness dependent. By contrast, the influence of metallic substrates on chemical state of polyurethanes and epoxies is stablished. It is well-known that native metal surfaces affect the chemical states of the adhesive in the region close to substrate/adhesive interphase [24, 25]. Based on this scenario, it is quite acceptable to propose a chemical state gradient of the adhesive layer as a function of the proximity to the steel surface. Likewise, thicker adhesive layers tend to be less affected by this chemical state gradient (adhesive).

Figure 3 presents the shear modulus for each tested condition of adhesive layer thickness. Effective moduli (shear moduli) were obtained from shear stress x strain curves at $0.5 \%$ strain. Thinnest adhesive layer presented the lowest value of shear modulus. Increased adhesive thickness lead to increasing of shear modulus, in accordance with reported results by JOHLITZ [1]. Our results revealed, therefore, the size effect for this lignin-containing polyurethane. Additionally, all samples presented cohesive failure. 


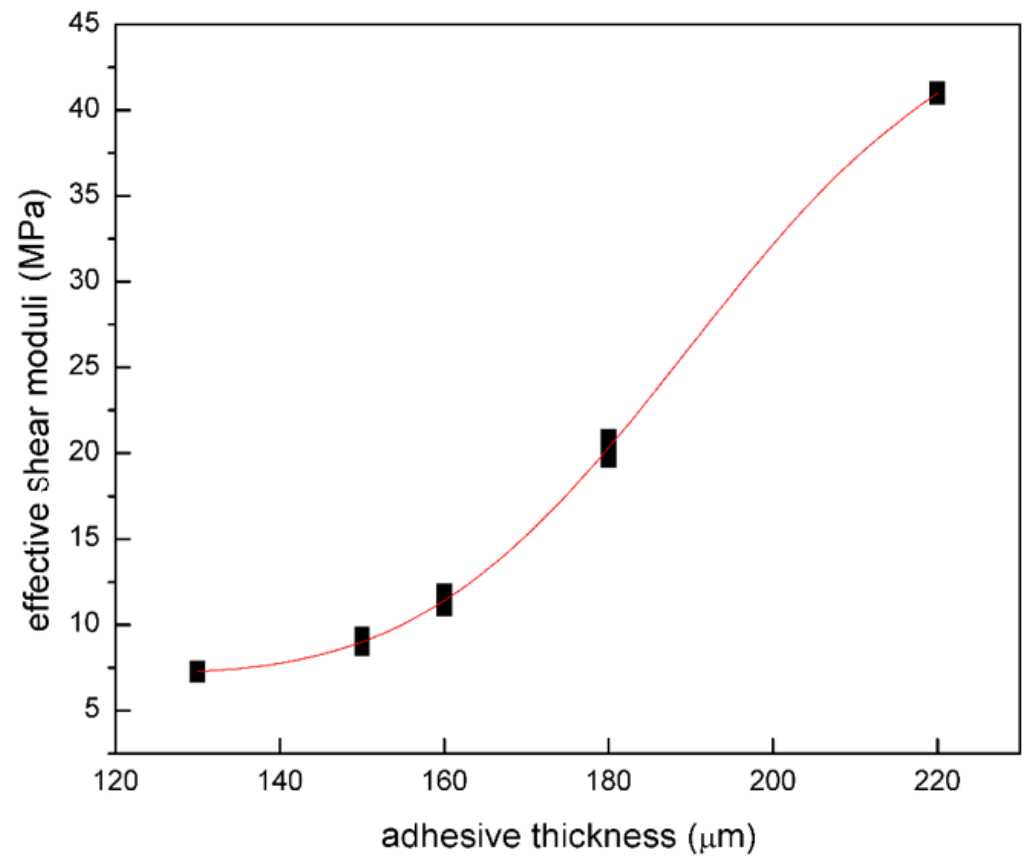

Figure 3: Effective modulus as function of bondline thickness.

Although shear modulus values were obtained at $0.5 \%$ strain under finite deformation to investigate the size effect, single lap shear experiments were carried out until specimen rupture. Average shear stresses are reported in Table 2. Since the shear stress distribution may not be constant over the entire overlap length, the measured value (experimental) represents in fact the average shear stress (the average strength of the adhesively bonded joints). The maximum shear stress followed the same trend observed for the shear modulus, increasing with the bondline thickness.

Table 2: Measured maximum (average) shear stress.

\begin{tabular}{l|c|c|c|c|c}
\hline Specimen & A1-B1 & A2-B2 & A3-B3 & A4-B4 & A5-B5 \\
\hline Thickness $(\boldsymbol{\mu m})$ & 130 & 150 & 160 & 180 & 220 \\
\hline $\boldsymbol{\tau}$ avg $(\mathbf{M P a})$ & $(3.32 \pm 0.45)$ & $(3.47 \pm 0.46)$ & $(3.68 \pm 0.59)$ & $(4.61 \pm 0.43)$ & $(4.73 \pm 0.40)$ \\
\hline
\end{tabular}

\subsection{Simulated mechanical behavior}

Figure 4 shows simulated shear stress distribution for adhesive layers, based on several models: 2D FEM, Volkersen and Goland-Reissner models. Measured shear stress and shear modulus were used as input parameters. The Poisson's ratio of the adhesive was assumed as 0.37 [26]. Volkersen and Goland-Reissner models consider the following parameters for stress distribution determination: adhesive and substrate dimensions, mechanical properties. These models are described in details elsewhere [21]. Results presented normalized shear stress as function of overlap length, for which $\mathrm{X} / \mathrm{C}=0$ is the middle point of the total overlap (40 mm). Likewise, $\mathrm{X} / \mathrm{C}=1.0$ represents the edges of the bonded length. Moreover, normalized shear stress was obtained as a ratio of average shear stress $\left(\tau_{\mathrm{avg}}\right)$ and local shear stress $\left(\tau_{\mathrm{c}}\right)$.

Volkersen and Goland-Reissner simulations were carried out in two conditions: i. Considering the shear modulus $\left(\mathrm{G}_{\mathrm{a}}\right)$ as infinitely high, i.e., substrate is not affected by the applied shear loading (constant $\mathrm{k}=1)$ and; ii. Assuming the engineering adherent shear modulus $(\mathrm{k}=0)$, where $\mathrm{k}$ is a model parameter related to the substrate shear modulus. In this context, Figure 4a-b revealed a complete convergence between simulations using Volkersen and Goland-Reissner models. In contrast, FEM simulation suggests a higher shear stress concentration at overlap ends in comparison to analytical models. 

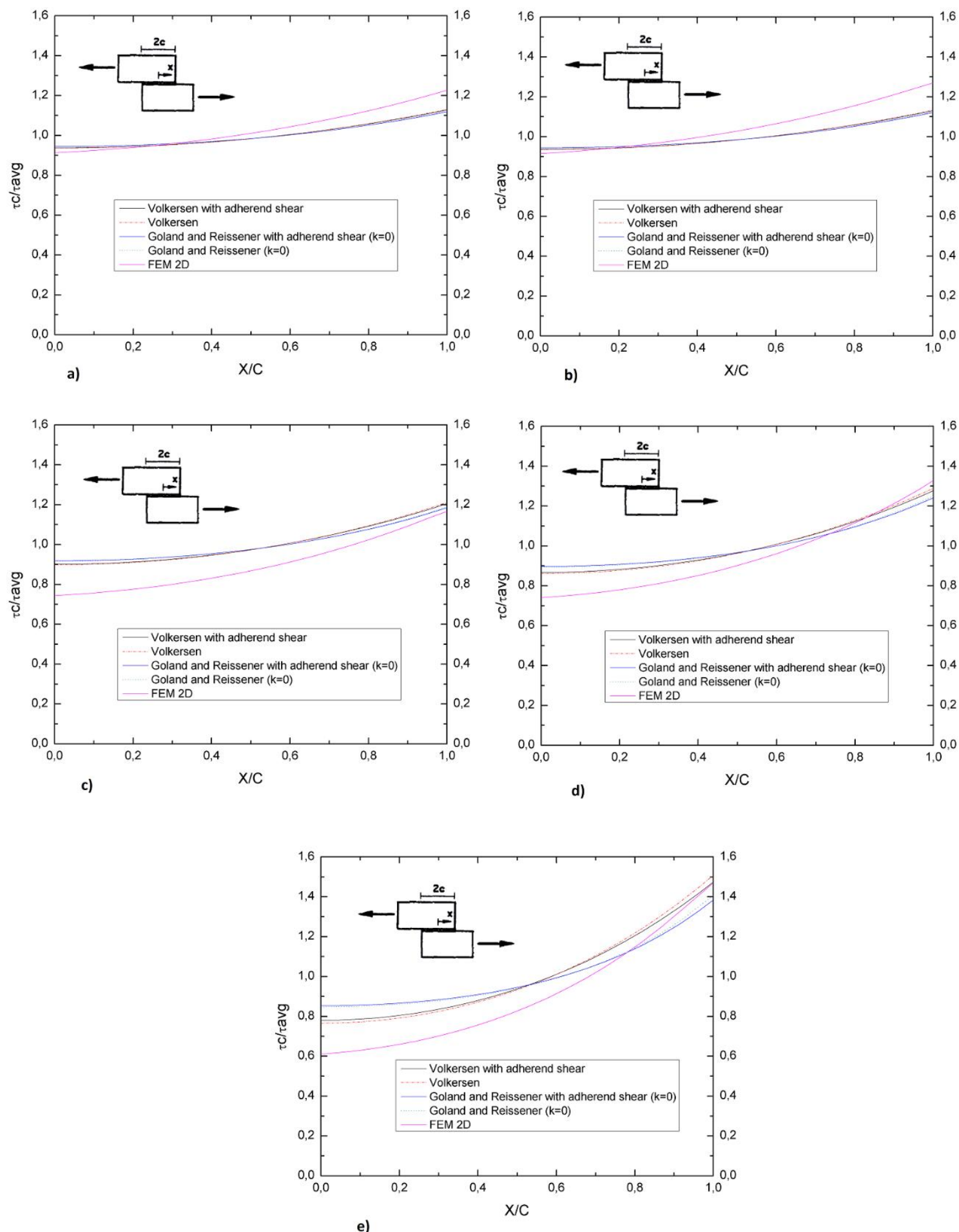

Figure 4: Normalized adhesive shear stress distributions of thick-adherend single-lap joint predicted by 1-D bar model (Volkersen), 1-D beam model (Goland and Reissner), the present 1-D bar model (Volkersen with adherend shear), the present 1-D beam model (Goland and Reissener with adherend shear) and 3-D finite element model (FEM). a) $130 \mu \mathrm{m}, \mathrm{b}$ ) $150 \mu \mathrm{m}$, c) $160 \mu \mathrm{m}, \mathrm{d}) 180 \mu \mathrm{m}$, and e) $220 \mu \mathrm{m}$.

Simulations of adhesive layers with thickness of $160 \mu \mathrm{m}$ and higher (Figure $4 \mathrm{c}-\mathrm{e}$ ) developed similar levels of local shear stress at overlap edges. Mechanical behavior of thicker adhesive layers is governed by bulk properties, as the thickness of affected bondline (interphase with metal) is insignificant in comparison with the total thickness of the adhesive. In this sense, simulations considering material isotropy seem to be more effective for thicker adhesive layers. The mechanical behavior of adhesively bonded joint was simulated. Simulations based on analytical models were in agreement, considering or even neglecting substrate de- 
formation, indicating that substrates (steel plates with high thickness) provided infinitely high shear modulus when compared to adhesive shear modulus.

\section{CONCLUSIONS}

Size effect was verified for lignin-containing polyurethane adhesive, in spite of its multiphase composition, since shear modulus of lignin-containing was affected by the thickness of the adhesive layer. Thicker adhesive layers presented higher average shear strength. Simulated results converge with experimental ones for thicker adhesive layers, for which bulk properties are predominant. Thinner adhesive layers are strongly affected by the steel surface and are not well represented by isotropic continuum simulations. Results can support further investigations and technological applications of lignin-containing adhesives.

\section{AKNOWLEGMENTS}

This work was funded by The São Paulo Research Foundation - FAPESP (grant number 2017/22936-9). The authors thank CAPES (Brazilian Federal Agency) and Federal University of ABC (UFABC) for the doctoral fellowship for P. H. Lixandrão Fernando (CAPES: 1794503).

\section{BIBLIOGRAPHY}

[1] JOHLITZ, M., DIEBELS, S, BATAL, J. et al. "Size effects in polyurethane bonds: Experiments, modelling and parameter identification," Journal of Materials Science., v. 43, n. 14, pp. 4768-4779, may 2008.

[2] JOHLITZ, M., DIEBELS, S, LION, A et al., "Modelling of viscoelastic material behaviour close to the glass transition temperature," Proceedingds in Applied Mathematics and Mechanics, v. 9, pp. 351-352, 2009.

[3] IZARU, L., ELEJANARRIETA, M. J. "The effect of the viscoelastic film and metallic skin on the dynamic properties of thin sandwich structures," Composite Structures, v. 176, pp. 407-419, may 2017.

[4] REZA, A., SHLSHESAZ, M. "The effect of viscoelasticity on the stress distribution of adhesively singlelap joint with an internal break in the composite adherends," Mechanics of Time-Dependent Materials, pp. 127, september 2017.

[5] SANTOS, D. J., BATALHA, G. F. "Failure criterion for adhesively bonded joints using Arcan's experimental method,” Polímeros, v. 24, n. 2, pp. 1-5, 2014.

[6] SOUSA JUNIOR, R. R., GOUVEIA, J. R., ITO, N. M. et al. "Failure prediction of hybrid composite using Arcan's device and Drucker-Prager model," Polymer testing, v. 58, p. 256-261, 2017.

[7] TAVARES, L. B., BOAS, C. V., SCHLEDER, G. R. et al. "Bio-based polyurethane prepared from Kraft lignin and modified castor oil, "Express Polymer Letters", v. 10, n. 11, pp. 927-940, june 2016.

[8] NACAS, A. M., ITO, N. M., SOUZA JUNIOR, R, R, et al. "Effects of NCO:OH ratio on the mechanical properties and chemical structure of Kraft lignin-based polyurethane adhesive," The Journal of Adhesion, vol. 93, n. 1-2, pp. 18-29, 2017.

[9] GOMIDE, J. L., COLODETTE, J. L., OLIVEIRA, R. C. et al. "Technological characterization of the new generation of Eucalyptus clones in Brazil for kraft pulp production," Revista Árvore, v. 29, n. 1, pp. 129-137, 2005.

[10] NASEEM, A., TABASUM, S., ZIA, K. M., et al. “ Lignin-derivatives based polymers, blends and composites : A review,” International Journal of Biological Macromolecules, v. 93, pp. 296-313, 2016.

[11] SAMENI, J., KRIGSTIN, S., JAFFER, S. et al. " Preparation and characterization of biobased microspheres from lignin sources," Industrial Crops \& Products, vol. 117, pp. 58-65, march 2018.

[12] BERNARDINI, J., CINELLI, P., ANGUILLESI, I. et al. "Flexible polyurethane foams green production employing lignin or oxypropylated lignin,” European Polymer Journal, v. 64, pp. 147-156, 2015.

[13] SUGANO-SEGURA, A. T. R., TAVARES, L. B., RIZZI, J. G. F. et al., "Mechanical and thermal properties of electron beam-irradiated polypropylene reinforced with Kraft lignin," Radiation Physics and Chemistry, v. 139, pp. 5-10, may 2017.

[14] GHAFFAR, S. H., FAN, M., "Lignin in straw and its applications as an adhesive," International Journal of Adhesion \& Adhesives, v. 48, pp. 92-101, 2014.

[15] HAYATI, A. N., EVANS, D. A. C., MARTIN, D. J. et al. "A simple methodology for improving the performance and sustainability of rigid polyurethane foam by incorporating industrial lignin," Industrial 
Crops \& Products., v. 117, pp. 149-158, march 2018.

[16] SANTOS, D. J., BATALHA, G. F. "Mechanical behaviour characterizing and simulation of polyacrylate rubber," Journal of Achievements in Materials and Manufacturing Engineering, v. 38, n. 1, pp. 33-40, 2010.

[17] UNGUREANU, D., TARANU, N., LUPASTEANU, V. et al., "Experimental and numerical investigation of adhesively bonded single lap and thick adherents joints between pultruded GFRP composite profiles," Composites Part B: Engineering, v. 146, pp. 49-59, 2018.

[18] YANG, C., TOMBLIN, J. S., GUAN, Z., "Analytical Modeling of ASTM Lap Shear Adhesive Specimens," In.: Report DOT/FAA/AR-02/130, Federal Aviation Administration, Washington, D.C., 2003.

[19] ASSOCIAÇÃO BRASILEIRA DE NORMAS TÉCNICAS. NBR 4287:2002: Especificações geométricas do produto (GPS) - Rugosidade: Método do perfil - Termos, definições e parâmetros da rugosidade. Rio de Janeiro. 2002.

[20]AMERICAN SOCIETY FOR TESTING AND MATERIALS. ASTM D 1002-99: Standard test method apparent shear strength of single-lap-joint adhesively bonded metal speciments by tension loading (metal-tometal). United States. 1999.

[21] DILL, ELLIS H., The Finite Element Method for Mechanics of Solids with ANSYS Applications. 1 ed ., New York, Taylor \& Francis Group, 2011.

[22] TSAI, M M. Y., OPLINGER, D. W., MONRTON, J. "Improved Theorical Solutions for adhesive lap joints," International Journal of Solids and structures., v. 35, n. 12, pp. 1163-1185, 1998.

[23] CARPENTER, W. C. "Goland and reissner were correct," The Journal of Strain Analysis for Engineering Design, v. 24, n. 3, pp. 185-187, 1989.

[24] DIEBELS, S., JOHLITZ, M., STEEB, H. et al. "A continuum-based model capturing size effects in polymer bonds," Journal of Physics: Conference Series, v. 62, n. 1, pp. 34-42, 2007.

[25] ITO, N. M., GOUVEIA, J. R., VIDOTTI, S. E. et al. "Interplay of polyurethane mechanical properties and practical adhesion of flexible multi-layer laminates," The journal of adhesion., v. 94, n. 11, pp. 1-14, 2019.

[26] ADAMS, R. D., PEPPIATT, N. A. "Effects of poisson's ratio strains in adherend on stresses of an idealized lap joint," Instituition of Mechanical Engineers.,v. 8, pp. 134-139, 1973.

\section{ORCID}

Paulo Henrique Lixandrão Fernando

https://orcid.org/0000-0002-2460-5878

Cleber Lucius da Costa

Kelly Cristina de Lira Lixandrão

https://orcid.org/0000-0002-9349-0541

Demetrio Jackson dos Santos

https://orcid.org/0000-0003-1969-7402

https://orcid.org/0000-0002-4707-2285 